Género y derechos laborales: servicio doméstico y trabajo doméstico no remunerado en la Justicia laboral en Argentina (1956-1974) Inés Pérez

páginas / año 6 - n 12 / ISSN 1851-992X / pp. 67-82 / 2014

http://paginas.rosario-conicet.gob.ar/ojs/index.php/RevPaginas

\title{
Género y derechos laborales: servicio doméstico y trabajo doméstico no remunerado en la Justicia laboral en Argentina (1956-1974)
}

Inés Pérez

CONICET/ Universidad Nacional de Mar del Plata

\begin{abstract}
Resumen
La cercanía entre el servicio doméstico y el trabajo doméstico no remunerado fue utilizada de manera recurrente a lo largo del siglo XX para limitar los derechos laborales de las trabajadoras domésticas. Sin embargo, las trabajadoras domésticas también apelaron a ella en demandas de reconocimiento del valor del trabajo realizado para sus empleadores. En este artículo, examino la forma en que distintos actores usaron dicha cercanía, ya para negar, ya para reivindicar, distintos derechos. En particular, me concentro en las estrategias de empleadores y trabajadoras domésticas desarrolladas frente a dos instituciones judiciales: el Tribunal del Trabajo Doméstico, con jurisdicción para la ciudad de Buenos Aires, y un tribunal del trabajo del Departamento Judicial de Mar del Plata.
\end{abstract}

\section{Palabras clave}

trabajo doméstico, servicio doméstico, género, justicia

\begin{abstract}
Domestic service's proximity to unpaid domestic labor was recurrently used throughout the twentieth century to restrict domestic workers' labor rights. However, in her demands for the recognition of their work's value, domestic workers also appealed to it. In this article, I examine how different actors used this proximity either to deny or to vindicate different rights in labor courts. In particular, I focus on both domestic workers' and employers' strategies developed within two judicial institutions: the Domestic Work Tribunal, that ruled in the city of Buenos Aires, and a labor court of the Judicial Department of Mar del Plata.
\end{abstract}

\section{Keywords}

domestic work, domestic service, gender, justice 


\section{Género y derechos laborales}

Buenos Aires, diciembre de 1959. A se presenta ante el Tribunal del Trabajo Doméstico. Reclama salarios y aguinaldos adeudados, además de indemnización por preaviso, originados en una relación de trabajo con B, para quien dice haberse desempeñado como empleada doméstica sin retiro entre julio y diciembre de ese año. En enero de 1960, B contesta la demanda, indicando que A no había sido su empleada, sino una huésped en su casa, a quien su esposa había prestado una habitación en comodato y que si "en agradecimiento, ha[bía] barrido la vereda o limpiado alguna pieza e[ra] lo menos que podía hacer" frente al favor que le habían hecho. Después de distintas audiencias, el tribunal falla a favor de A, condenando a B a pagarle 1735 pesos. B apela en mayo de 1960 y, meses más tarde, un juez de segunda instancia revoca la sentencia del tribunal de primera instancia, sosteniendo que A no había probado que había trabajado sin retiro para B, y por tanto no tenía derecho al monto reclamado, condenando a ambas partes a pagar las costas del proceso judicial. ${ }^{1}$

Mar del Plata, septiembre de 1970. El tribunal de trabajo no. II de Mar del Plata emite un fallo en la causa que $G$ había iniciado contra $F$, en la que sostenía que había trabajado como mucama en la pensión Madrid, propiedad de F, y que por ese trabajo se le adeudaba un total de 370.450 pesos $\mathrm{m} / \mathrm{n}$. En su defensa, F sostuvo que, si bien G había trabajado para él, lo había hecho en calidad de empleada doméstica de la familia, no de mucama de hotel. Sostuvo, además, que en el establecimiento sólo se alojaban 5 huéspedes, que limpiaban sus propias habitaciones y lavaban su ropa. El tribunal hace lugar parcial a la demanda, entendiendo que G efectivamente trabajó como empleada doméstica, y condenando a $\mathrm{F}$ a pagar la suma de 8.400 pesos m/n (362.050 pesos menos que los inicialmente demandados). ${ }^{2}$

Buenos Aires, febrero de 1971. H se presenta ante el Consejo del Trabajo Doméstico. Demanda a Z por dinero que le adeudaba por el trabajo que realizara para ella como empleada doméstica entre abril de 1964 y diciembre de 1970. H sostiene que trabajaba 5 días a la semana, 4 horas por día, encuadrándose en el régimen del servicio doméstico aprobado unos años antes. Unos días más tarde, se realiza una audiencia de conciliación. Allí, $\mathrm{Z}$ reconoce que $\mathrm{H}$ había trabajado para ella, pero sostiene que sólo lo había hecho 2 horas y media por día y que, en ese sentido, "no la unía ninguna relación de servicio doméstico" con $\mathrm{H}$ sino "lo que jurídicamente constitu[ía] una locación de servicios", lo que suponía que H no tenía derecho al dinero reclamado. $\mathrm{H}$ se retira de la audiencia. El Consejo la declara en rebeldía y archiva su denuncia. ${ }^{3}$

\footnotetext{
${ }^{1}$ Acta 337/1959, Tribunal del Trabajo Doméstico, Archivo General de la Nación.

${ }^{2}$ Sentencia del expediente 7254, Registro de Sentencias del Tribunal del Trabajo No. II del Departamento Judicial de Mar del Plata.

${ }^{3}$ Acta 7/1971, Tribunal del Trabajo Doméstico, Archivo General de la Nación.
} 


\section{Inés Pérez}

II

En estos tres casos, vemos mujeres que presentan demandas ante las autoridades judiciales, reclamando derechos derivados de su trabajo. En los tres, las mujeres tienen dificultades para probar la relación de trabajo que mantenían con sus empleadores, lo que redunda en una limitación a sus reclamos iniciales. En todos ellos, se trata de distintas formas de lo que podríamos llamar "servicio doméstico". Las dificultades para probar la relación con los empleadores se derivan de la invisibilidad de ese trabajo.

¿En qué sentido era "invisible"? Como ha señalado Romina Cutuli, a diferencia de otros empleos, aquí el hecho de que un testigo asegurara haber visto a la trabajadora en el lugar de trabajo no era evidencia necesaria de que existiera una relación de trabajo, ni de cuál era su carácter. ${ }^{4}$ Estos elementos se vinculan con la cercanía de ese trabajo al realizado por las mujeres en sus hogares sin una remuneración a cambio. Si la presencia de la trabajadora en casa del empleador podía ser explicada por una relación de carácter amistoso o familiar, incluso si era vista realizando tareas domésticas, los tribunales podían asumir que eran realizadas gratuitamente en virtud de esa relación.

Ahora bien, la cercanía entre el servicio doméstico y el trabajo doméstico no remunerado fue fruto de una construcción histórica que implicó, entre otras cosas, una redefinición y una estratificación de las ocupaciones agrupadas bajo ese rótulo. Si lo largo del siglo XX el trabajo asalariado fue asociado al reconocimiento de los derechos sociales, el servicio doméstico fue pobre y tardíamente incluido bajo las protecciones garantizadas por esos derechos, en un proceso lento, ambiguo y no lineal, que implicó su feminización, así como su separación de algunas ocupaciones especializadas que anteriormente eran consideradas parte de este tipo de trabajo. ${ }^{5}$

Los términos utilizados para nombrar las actividades agrupadas bajo la categoría "servicio doméstico" y las personas que las desarrollan han variado a través del tiempo y el espacio. Bajo el rótulo "servicio doméstico" se han incluido ocupaciones sumamente diversas, como la de valet, cochero, ama de llaves, cocinera, etc. ${ }^{6}$ Incluso en la actualidad, se lo utiliza para designar personas con actividades diversas, que pueden incluir desde el cuidado de niños hasta el arreglo de jardines. Como ha sostenido Edward Higgs, quizá más que mirar el servicio doméstico como una "ocupación", sería conveniente estudiarlo como una serie de

\footnotetext{
${ }^{4}$ Romina Cutuli, "Desigualdades en el acceso a la justicia: un "régimen de invisibilidad". El servicio doméstico en la provincia de Buenos Aires (1990-2010)". Primer Congreso Latinoamericano de Historia de las Mujeres, Buenos Aires, 20 y 21 de septiembre 2012 [1-17].

${ }^{5}$ Raffaella Sarti, "Domestic Service since 1750", Gender \& History, Vol. 18, № 2, 2006 [187198]; Inés Pérez, "Un "régimen especial" para el servicio doméstico. Tensiones entre lo laboral y lo familiar en la regulación del servicio doméstico en la Argentina, 1926-1956", Cuadernos del IDES, en prensa.

${ }^{6}$ Cecilia Allemandi, "El servicio doméstico en el marco de las transformaciones de la ciudad de Buenos Aires, 1869-1914", Diálogos, Vol. 16, No. 2, 2012 [385-415].
} 


\section{Género y derechos laborales}

relaciones sociales con un contenido de trabajo similar en un espectro que va desde el parentesco cercano al vínculo económico. ${ }^{7}$

Las discusiones en torno de la definición de la categoría "trabajo" tienen una larga tradición en las Ciencias Sociales. Su asociación a la condición salariada implicó que aquellas actividades que no ingresaran claramente en ella fueran tenidas social y jurídicamente como "no trabajo". ${ }^{8}$ Desde el feminismo, el célebre debate en torno de del "trabajo doméstico" que tuviera lugar en los años setenta puso en tela de juicio esta restricción conceptual a fin de incluir aquellas actividades que tradicionalmente las mujeres realizaban dentro del espacio doméstico sin una remuneración a cambio. ${ }^{9}$

Sin embargo, el "servicio doméstico" siguió ocupando una zona gris en torno a esas clasificaciones. Su caracterización como una actividad "no productiva" en los inicios del pensamiento económico moderno se articuló con una larga tradición que lo ubicaba en el ámbito de las relaciones familiares, más que en el de las laborales. ${ }^{10}$ Estos elementos redundaron en una tardía protección legal de las trabajadoras de este sector en buena parte del globo, así como en la sanción de derechos laborales más restringidos en relación a los reconocidos a otros trabajadores. ${ }^{11}$

Las dificultades para garantizar distintos derechos laborales para las trabajadoras domésticas dependieron en buena medida de la cercanía de su trabajo con el mundo familiar $y$, en particular, con el trabajo doméstico no remunerado. La imagen de que el trabajo doméstico no es realmente un trabajo responde a una mirada androcéntrica del trabajo que dominó el campo del derecho laboral desde principios del siglo XX. ${ }^{12}$ Sin embargo, la cercanía con el trabajo doméstico no remunerado y con la figura del ama de casa también fue utilizada por las trabajadoras en demandas de reconocimiento del valor (no estrictamente monetario) de las tareas realizadas para sus empleadores.

En este artículo, examino los usos que distintos actores hicieran de la cercanía del servicio doméstico y el trabajo doméstico no remunerado, ya para negar, ya para reivindicar, distintos derechos. En particular, me concentro en las estrategias de empleadores y trabajadoras domésticas desarrolladas frente a dos instituciones de justicia laboral en la Argentina: el Tribunal del Trabajo Doméstico, con jurisdicción para la capital federal, y un tribunal del trabajo del Departamento

\footnotetext{
${ }^{7}$ Edward Higgs, "Women, Occupations and Work in the Nineteenth Century Censuses", History Workshop, No. 23, Spring 1987 [59-80].

${ }^{8}$ Robert Castel, El ascenso de las incertidumbres. Trabajo, protecciones, estatuto del individuo. Buenos Aires, FCE, 2010.

${ }^{9}$ Dinah Rodríguez y Jennifer Cooper (Comps.), El debate sobre el trabajo doméstico, México, UNAM, 2005.

${ }^{10}$ Carolyn Steedman, Labours Lost. Domestic Service and the Making of the Modern England. Cambridge, Cambridge University Press, 2009.

${ }^{11}$ Adelle Blackett, "Introduction: Regulating Decent Work for Domestic Workers", en Canadian Journal of Women and Law, No. 23 [1-47].

${ }^{12}$ Inés Pérez, ob. cit.
} 


\section{Inés Pérez}

Judicial de Mar del Plata. ${ }^{13}$ Centro mi mirada en el período marcado entre la sanción del primer régimen laboral para el servicio doméstico, en 1956, y la sanción de la Ley de Contrato de Trabajo, en 1974. Antes, sin embargo, reconstruiré los caminos por los que el servicio doméstico fue asociado en términos legales al trabajo doméstico no remunerado, habilitando tales usos.

III

En Argentina, el decreto 326 de 1956 introdujo el primer estatuto para el servicio doméstico, que tuvo un carácter de "régimen especial". A pesar de que desde las primeras décadas del siglo se presentaron distintos proyectos al Congreso que buscaban reglamentar y otorgar algunos derechos laborales a este sector, sólo en 1955, un año antes de la sanción de dicho decreto, uno de ellos alcanzaría media sanción, en un proceso interrumpido por el golpe de estado de ese año. ${ }^{14}$

Para entonces, la legislación laboral tenía una larga trayectoria en Argentina. Las transformaciones sociales que comenzaran en las últimas décadas del siglo XIX, vinculadas a la intensidad del crecimiento urbano y del trabajo industrial, así como al desarrollo del movimiento obrero, marcaron un escenario frente al se buscó dar respuesta a partir de la legislación laboral. ${ }^{15}$ El servicio doméstico, sin embargo, fue excluido de esta legislación. Su inclusión dentro del alcance de algunos de esos derechos fue tardía y se focalizó sólo en algunos de los trabajadores y trabajadoras del sector.

La exclusión del servicio doméstico de las protecciones garantizadas a otros trabajadores resulta significativa por distintas razones, una de las cuales es su relevancia en el mercado de trabajo. En Argentina, a pesar de su descenso relativo

\footnotetext{
${ }^{13}$ El Tribunal del Trabajo Doméstico (inicialmente llamado Consejo del Trabajo Doméstico) fue creado en 1956 para resolver conflictos derivados del trabajo doméstico. A diferencia de los tribunales de trabajo regulares, creados en 1944, éste era un tribunal de conciliación que dependía del Ministerio de Trabajo de la Nación, dedicado exclusivamente a los conflictos surgidos de un sector laboral. En este sentido, la mirada sobre un tribunal de trabajo regular me permite observar algunas tensiones que no están presentes en el Tribunal del Trabajo Doméstico, como aquellas que se despiertan en torno a la categoría laboral de las trabajadoras. En este sentido, tomo uno de los tribunales laborales de la ciudad de Mar del Plata como ejemplo de las trayectorias judiciales de las trabajadoras domésticas en una ciudad de la provincia de Buenos Aires. Resulta imprescindible, sin embargo, señalar que, mientras se conservan buena parte de las actas completas iniciadas ante el Tribunal del Trabajo Doméstico, no ocurre lo mismo con los tribunales laborales de la provincia, de los que sólo se conservan registros de sentencias. Para una historia de los tribunales laborales de la provincia de Buenos Aires, ver Andrés Stagnaro, "Los Tribunales del Trabajo como escenario del conflicto entre el capital y el trabajo. 1948-1960", Tesis doctoral, Universidad Nacional de La Plata, 2012.

${ }^{14}$ Ania Tizziani, "El Estatuto del Servicio Doméstico y sus antecedentes: debates en torno a la regulación del trabajo doméstico remunerado en la Argentina", Nuevo mundo, mundos nuevos, 2013 [1-15].

${ }^{15}$ Andrés Stagnaro, "Los tribunales de...", ob. cit.; Mirta Lobato y Juan Suriano, Trabajo, cuestión social e intervención estatal", en Lobato, Mirta y Juan Suriano (comps.), La sociedad del trabajo. Las instituciones laborales en la Argentina (1900-1955), Buenos Aires, Edhasa, 2014.
} 


\section{Género y derechos laborales}

-explicado por el crecimiento de otras ocupaciones, en especial en la industria y el comercio- y de los cambios en las ocupaciones incluidas bajo este rótulo, el servicio doméstico sería uno de los sectores que más mujeres ocuparía dentro del mercado de trabajo durante todo el siglo XX.16

El decreto ley 326, en este sentido, marcó un hito de relevancia, en tanto reconoció distintos derechos laborales a quienes se ocupaban en el servicio doméstico, como las vacaciones y la licencia por enfermedad, y mantuvo otros que ya habían sido sancionados, como el salario anual complementario. Sin embargo, los derechos reconocidos a este sector eran limitados en comparación a los garantizados contemporáneamente a otros trabajadores y trabajadoras. Los días de vacaciones y licencias, así como los montos de las indemnizaciones eran, por ejemplo, sustancialmente menores que los de otros trabajadores. Del mismo modo, las empleadas domésticas eran excluidas de las protecciones a la maternidad garantizadas a otras trabajadoras.

¿Cómo se justificaron estas limitaciones? ¿Qué explica que el servicio doméstico fuera regulado mediante un "estatuto especial"? La figura del régimen especial para este sector había sido introducida en los debates parlamentarios en la década de 1920. Si hasta entonces los proyectos que habían buscado regular este trabajo habían propuesto modificaciones a regulaciones de carácter general que explícitamente lo excluían, a partir de mediados de los años veinte comenzó a sostenerse que debía sancionarse una ley que regulara de manera íntegra "este trabajo tan particular y especial". A partir de entonces, y aunque no sería sostenida de manera unánime, la figura del régimen especial ganaría fuerza tanto en la doctrina como en los proyectos presentados al Congreso. ${ }^{17}$

Qué era lo que definía la particular "naturaleza" del servicio doméstico, sin embargo, sería materia de debate, en relación a las discusiones en torno de los límites de dicha ocupación. La convivencia con el empleador y su familia fue uno de los elementos señalados de manera recurrente para marcar las particularidades de este trabajo, presentada como una de sus características intrínsecas, a los que la ley debía adaptarse. Para mediados de la década de 1920, el empleo sin retiro era la forma más habitual del servicio doméstico. En este sentido, la habitación y el alimento eran considerados parte del salario, lo que implicaba una disminución del salario en dinero. La presencia de la trabajadora en el hogar de sus empleadores y el tipo de actividades desarrolladas -tendientes a satisfacer sus necesidades cotidianas-, por otra parte, daba lugar a jornadas de trabajo más extensas. Por

\footnotetext{
${ }^{16}$ Mirta Lobato, Historia de las Trabajadoras en la Argentina (1869-1960), Buenos Aires, Edhasa, 2007; Carlos Zurita, "Trabajo, servidumbre y situaciones de género. Algunas acotaciones sobre el servicio doméstico en Santiago del Estero, Argentina", Programa de Investigaciones sobre Trabajo y Sociedad (PROIT) del Instituto de Desarrollo Social (INDES) de la Universidad Nacional de Santiago del Estero (UNSE) [sin fecha].

${ }^{17}$ Inés Pérez, ob. cit.
} 


\section{Inés Pérez}

último, la convivencia también suponía una relación de intimidad que podía suponer una amenaza a la moralidad (o incluso a la salud) de los empleadores. ${ }^{18}$ Sin embargo, a fines de la década de 1930, la convivencia no era universalmente aceptada como la característica definitoria de este trabajo. Como ha mostrado Cecilia Allemandi, entre fines del siglo XIX y principios del siglo XX, el "servicio doméstico" estaba compuesto por distintas ocupaciones, que incluían desde "lavanderas", "amas de leche", "cocheros", "mozos", entre otras. ${ }^{19}$ Esta diversidad respondía a la amplitud con la que se definía al sector en las primeras décadas del siglo XX, cuyos límites no coincidían exactamente con los del mundo del hogar. En efecto, los casos identificados como dudosos eran aquéllos que tenían un vínculo más claro con el mundo "público". Esta distinción sería recuperada unos años más tarde con la sanción de la ley 12.631 que incorporó a los trabajadores y trabajadoras domésticas que no se desempeñaran exclusivamente al servicio personal de su empleador al régimen de accidentes de trabajo. ${ }^{20}$

Éstas no serían las únicas distinciones establecidas dentro del servicio doméstico. Entre los años cuarenta y cincuenta se excluiría de ese rótulo a algunos trabajadores (y el masculino aquí no es neutro) que, en las palabras de un relevante jurista de la época, eran "impropiamente denominados domésticos." En los años cuarenta distintas ocupaciones se desmarcaron del servicio doméstico. Ocupaciones que antes estaban bajo ese rótulo -como las de los choferes particulares, los limpiadores de salas de espectáculos, oficinas y casas particulares, o los encargados de casas de renta- ganaron un estatus independiente, garantizado por su vínculo, ya con saberes especializados, ya con el trabajo considerado "productivo". En términos generales, dicha redefinición implicó la separación de ocupaciones identificadas como "masculinas" del "servicio doméstico" y, en este sentido, contribuyó a la feminización del sector. ${ }^{21}$

Estas demarcaciones tuvieron como correlato una redefinición del "servicio doméstico" operada a partir de nociones androcéntricas de "trabajo", que para mediados de siglo quedó identificado con la "empleada de hogar para todo servicio". Su feminización -que se había iniciado a fines del siglo XIX y que sería profundizada durante la primera mitad del siglo XX - fue acompañada de un refuerzo de su identificación como una ocupación "no calificada" y que no generaba lucro o ganancia al empleador. Lo que resulta más significativo es que para mediados de siglo, los límites del servicio doméstico parecían coincidir más claramente con los del hogar del empleador como lugar de trabajo.

\footnotetext{
${ }^{18}$ Ver, por ejemplo, el proyecto de ley para regular el servicio doméstico presentado por el diputado Tiburcio Padilla en 1934. Diario de sesiones de la Cámara de Diputados de la Nación, 18 de julio de 1934.

${ }^{19}$ Cecilia Allemandi, ob. cit.

${ }^{20}$ Leonardo Colombo, "Régimen jurídico del servicio doméstico", La ley, T. 15, agosto de 1939; Ley 12.631, Anales de legislación argentina 1920-1940, Buenos Aires, La ley, 1953.

${ }^{21}$ Ver, por ejemplo, la discusión en torno de la sanción de la ley 12.867, Diario de Sesiones de la Cámara de Diputados de la Nación, 27 y 28 de Septiembre de 1946, pp. 738-750; Diario de Sesiones de la Cámara de Senadores de la Nación, 30 de Septiembre de 1946, pp. 746-749.
} 


\section{Género y derechos laborales}

Sin embargo, desde mediados de la década del cuarenta, algunas normas de alcance general iniciaron una etapa caracterizada, en palabras de un jurista de la época, por "atribuir verdaderos derechos al servicio doméstico". ${ }^{22}$ Esta legislación fue de la mano de la presentación al Congreso de distintos proyectos para la regulación del servicio doméstico entre 1946 y 1948, que proponían regímenes integrales para el sector, pero incorporándolos a buena parte de los derechos ya reconocidos a otros trabajadores, como la reducción de la jornada laboral, las licencias por maternidad y enfermedad, y el régimen de accidentes de trabajo. ${ }^{23}$

Ahora bien, este movimiento encontraría un freno con la sanción del decreto ley 326 en 1956, que volvería a dar centralidad a la idea de un régimen especial. Tanto en este decreto como en el debate del proyecto que alcanzara media sanción el año anterior se pondría el acento en las particularidades de este trabajo derivadas del tipo de relación establecida entre la trabajadora y la familia del empleador, que justificarían algunas limitaciones para los derechos laborales reconocidos. Casi veinte años después, en 1974, la Ley de Contrato de Trabajo estableció un piso de derechos laborales para el conjunto de los trabajadores y trabajadoras en la Argentina, las trabajadoras domésticas se contaron entre las pocas excepciones admitidas por dicha ley. La excepcionalidad de dicho trabajo, que implicó la limitación de los derechos laborales de las trabajadoras, seguía siendo justificada por las tensiones surgidas de la relación de la trabajadora con la familia del empleador.

IV

Como en los casos mencionados al inicio, el lugar ambiguo del servicio doméstico, entre el mundo laboral y el mundo familiar supuso, en términos generales, limitaciones, no sólo en el reconocimiento legislativo de derechos a estas trabajadoras, sino además, la dificultad de hacerlos valer frente a las instituciones de justicia. Dichas dificultades derivaban de la presunción de gratuidad del trabajo doméstico realizado por las mujeres en el marco de relaciones afectivo-familiares. Ahora bien, en el período previo a la sanción del decreto 326, no había un criterio único respecto de cuándo correspondía o no una remuneración por este tipo de trabajo.

Desde mediados de los años 1930 y durante la década de 1940, en diversas ocasiones los tribunales se enfrentaron a la necesidad de establecer en qué casos correspondía una remuneración a cambio de trabajo doméstico cuando existía una

\footnotetext{
${ }^{22}$ Julio C. Rojas, "El servicio doméstico. Régimen Jurídico", Tesis de Doctorado, Facultad de Derecho, UBA, 1956.

${ }_{23}$ Ver los proyectos del diputado radical Ernesto Sammartino (presentado en 1946), del diputado laborista Leandro Reynés (también presentado en 1946), y del diputado peronista Silverio Pontieri (presentado en 1948). Diario de Sesiones de la Cámara de Diputados de la Nación, 27 de junio de 1946, p. 99; Diario de sesiones de la Cámara de Diputados de la Nación, 1 de octubre de 1946, pp. 57-58; Diario de Sesiones de la Cámara de Diputados de la Nación, 12 de mayo de 1948, pp. 243-244.
} 


\section{Inés Pérez}

relación afectiva entre las partes. Los concubinos no casados, los amigos corresidentes y los criados, es decir niños y -sobre todo- niñas que no eran hijas de aquellos para quienes trabajaban pero que habían vivido con ellos desde edades muy tempranas, generaban situaciones confusas frente a las que los tribunales ensayaron distintas respuestas. ${ }^{24}$

Así, por ejemplo, en el número de septiembre de 1941, La Ley, la revista jurídica más importante de la época, comentaba un fallo de la Cámara Civil de la Capital Federal en el que se reconocía a una mujer el derecho a cobrar por el trabajo doméstico realizado en el marco de una relación de concubinato, luego de que quien fuera su concubino hubiera fallecido. A pesar de que en otro caso similar el mismo tribunal había sostenido que "el concubinato no autoriza[ba] a percibir sueldos en concepto de retribución de servicios" 25 , en éste, aunque no se reconocía su derecho a una parte de la herencia de quien fuera su concubino, el hecho de que la mujer en cuestión se hubiera desempeñado previamente como doméstica justificaba el pago de ese trabajo.

El decreto ley 326/56 buscó establecer un criterio único en relación a la gratuidad del trabajo doméstico, suponiéndola frente a vínculos afectivos y de estrecha solidaridad. Como marcaba un fallo de la Cámara de Apelaciones del Trabajo de la ciudad de Buenos Aires de 1970 comentado por distintas revistas jurídicas,

Que la ley, en principio, presuma la gratuidad de los servicios presados por personas que conviven bajo un mismo techo, se explica y justifica, desde que ello supone, en definitiva, justo homenaje a un sentimiento de amistad o gratitud, de concurrencia inadmisible con un propósito de lucro y que es deber del legislador considerar y hasta favorecerlo, si es posible. [...] la causal de exclusión contenida en el art. $2^{\circ}$ del decreto-ley 326/56 obedece al hecho de que, dentro del orden natural y corriente de las cosas, la realización de tareas domésticas en el hogar por parte de miembros de la familia, no obedece a la existencia de un contrato de trabajo sino a los vínculos afectivos y la estrecha solidaridad que media entre ellos...26

Siguiendo estos preceptos, en los expedientes iniciados ante distintas instituciones de justicia, de manera recurrente, los demandados buscaban situar el trabajo doméstico que las demandadas habían prestado en sus hogares en el marco de relaciones afectivo familiares, apelando a dicha presunción de gratuidad. Así, por ejemplo, ocurría en un expediente iniciado en 1962 frente al Tribunal del Trabajo Doméstico, en el que un demandado sostenía que la accionante "[...] pretend[ía] ampararse en un derecho que no le correspond[ía] ni la proteg[ía],

\footnotetext{
${ }^{24}$ Oscar Grinberg, "El servicio doméstico en el derecho argentino", Tesis para optar por el título de Doctor en Derecho y Ciencias Sociales, Buenos Aires, 1951, pp. 44-47.

${ }^{25}$ La ley, T.23, Septiembre de 1941, pp. 903.

${ }^{26}$ Revista de Seguridad Social, 1970, p. 1080. Ahora bien, estas consideraciones no implicaban que cualquier relación afectiva implicara gratuidad del trabajo doméstico. El concubinato seguía estando excluida de este "privilegio", en tanto era considerada una relación "inmoral" que no merecía la protección de la ley.
} 


\section{Género y derechos laborales}

pues en ningún momento ha[bía] sido personal de servicio ni a [sus] órdenes ni a los (sic) de [su] esposa. ${ }^{27}$ De acuerdo a su presentación, lo que explicaba la presencia de la demandante en su casa era una relación de amistad:

[...] atento la situación económica de la actora y el afecto que las había unido antes del casamiento, decidimos que viniera a vivir con nosotros a nuestra casa [...], incorporándose como un miembro más de la familia, al extremo que siempre se sentó a la mesa familiar, siempre ha estado presente en todos los actos de la familia y recibió el trato de una amiga, hasta que lamentablemente, ciertos actos de su conducta obligaron a que mi esposa se los recriminara, provocándose un estado de tirantez, que desembocó en que la actora se retirara de nuestra casa y como corolario de ello y con ánimo de vengarse, entablara esta temeraria acción. ${ }^{28}$

Las relaciones afectivo familiares podían ser, ya con la familia de los demandados, ya con alguien que se reconocía tenía un vínculo laboral con ellos. Un ejemplo de este tipo de argumentos puede encontrarse en un juicio desarrollado en el Tribunal de Trabajo No. II del Departamento Judicial de Mar del Plata, que llegara a sentencia en agosto de 1969, en el que el demandado, reconociendo que uno de los accionantes se había desempeñado como peón de campo a sus órdenes, negaba haber empleado a su esposa como cocinera. Si ella había sido vista desempeñando distintas tareas domésticas en su establecimiento, e incluso cocinando para otros trabajadores, el demandado sostenía que lo había hecho como parte de sus tareas como esposa del peón, no porque existiera un vínculo laboral entre ellos. En su sentencia, los jueces del tribunal entendieron, en el mismo sentido, que esos trabajos no le daban derecho a una retribución monetaria. ${ }^{29}$

La presunción de gratuidad también era frecuente en otro tipo de casos, donde los demandados insistían en que la presencia de las accionantes en sus domicilios no se explicaba por la existencia de una relación de trabajo, sino por otro tipo de relaciones. Puntualmente, entre fines de los años cincuenta y mediados de los años sesenta, era frecuente que los demandados presentaran a las accionantes como inquilinas. ${ }^{30}$ Así, en un expediente iniciado en 1960 frente al Tribunal del Trabajo Doméstico, la demandada sostenía que si bien la accionante había cuidado a sus hijas por las noches durante cuatro meses, no lo había hecho como trabajadora dependiente, sino en pago de una deuda que tenía con ella por haberle dado alojamiento en su casa. ${ }^{31}$

\footnotetext{
${ }^{27}$ Acta 18/ 1960, Tribunal del Trabajo Doméstico, Archivo General de la Nación. 28 Ídem.

${ }^{29}$ Sentencia del expediente 6731, Registro de Sentencias del Tribunal de Trabajo No. II del Departamento Judicial de Mar del Plata, Tomo II.

${ }^{30}$ Para un desarrollo de este argumento, ver Inés Pérez, "Entre las normas y sus usos. Servicio doméstico, trabajo, intimidad y justicia en el Consejo de Trabajo Doméstico (Buenos Aires, 1956-1962)", Nuevo Mundo, Mundos Nuevos, 2013 [1-16].

${ }^{31}$ Acta 108/1960, Tribunal del Trabajo Doméstico, Archivo General de la Nación.
} 


\section{Inés Pérez}

Como se desprende de este caso, quienes se desempeñaban en el servicio doméstico tenían dificultades no sólo para probar que habían trabajado para los demandados sino también las condiciones en las que lo habían hecho. El decreto ley 326/56 sólo amparaba a quienes habían trabajado al menos 4 horas 4 días a la semana para un mismo empleador. En este sentido, incluso cuando la trabajadora hubiera sido vista trabajando, eso no probaba la existencia de una relación laboral, a menos que pudiera probarse la frecuencia y el horario de trabajo. Este tipo de argumentos se volvería más frecuente hacia fines de los años sesenta, de la mano de un crecimiento del trabajo con retiro para distintos empleadores, en particular en la ciudad de Buenos Aires.

Del mismo modo, como veíamos en uno de los casos citados al inicio del artículo, los demandantes podían negar la categoría laboral de las demandantes, haciéndolas pasar por empleadas domésticas cuando cumplían tareas de limpieza, y a veces también de otro tipo, en espacios comerciales. De esta manera, buscaban pagar menos dinero por las demandas que las trabajadoras les iniciaban. ${ }^{32}$ Lo contrario, sin embargo, también era posible. El caso retratado en un expediente que llegara a sentencia en un tribunal laboral de Mar del Plata en 1965 resulta un buen ejemplo de este tipo de estrategias, frente a las que resulta difícil establecer cuál era la categoría laboral real de la trabajadora. En dicho expediente, la trabajadora reclamaba diferencias de salarios y otros rubros como empleada de comercio. Frente a su demanda, el empleador sostuvo que, si bien había trabajado para él, lo había hecho como doméstica. La confusión era posible porque la accionante había vivido en casa de sus empleadores y, según su declaración, también se había desempeñado como doméstica en el horario posterior a su desempeño como empleada en el comercio del empleador. Si bien los jueces aceptaron la versión del empleador, desestimando la demanda y obligando a la accionante a pagar las costas del juicio, la situación descripta por la trabajadora también era posible y ninguna de las versiones era plenamente probada por la evidencia citada. ${ }^{33}$

Ahora bien, la ambigüedad entre los mundos laboral y familiar en la que se hallaba el servicio doméstico también fue utilizada por parte de las trabajadoras para resaltar el valor de su trabajo. Aunque mediadas por la de sus abogados, la voz de las trabajadoras puede rastrearse en el detalle con que en algunas de las presentaciones ante las instituciones de justicia se describen de las labores por ellas realizadas. En un acta iniciada en septiembre de 1960, por ejemplo, el letrado sostenía que su representada:

atendió siempre con profunda lealtad los quehaceres domésticos de toda la familia, cocinaba para tres personas y sus amistades en distintas oportunidades, nunca se

\footnotetext{
${ }^{32}$ Para un desarrollo más completo de este argumento, ver Inés Pérez y Débora Garazi, "Mucamas y domésticas. Trabajo femenino, justicia y desigualdad (Mar del Plata, Argentina, 1956-1974)", Cadernos Pagú, No. 42, 2014

${ }^{33}$ Sentencia del Expediente 3688, Registros de Sentencias del Tribunal de Trabajo No. II de la ciudad de Mar del Plata, T. I.
} 


\section{Género y derechos laborales}

hacía una sola comida y se debía amasar frecuentemente para los postres -servía la mesa en todas las oportunidades necesarias- limpiaba pisos - lavaba toda la ropa de cama y personal de todos los miembros de la familia - planchaba toda la ropa tanto de cama como individuales - limpiaba y planchaba los trajes etc de toda la familia realizando estas tareas desde las siete hasta las veintidós horas corridas y jamás puso inconvenientes por el descanso que legalmente le correspondía, o exigió las doce horas de labor diaria que señala la ley ni siquiera realizó reclamación alguna por el descanso semanal correspondiente; servía así con abnegación, lealtad, honradez, eficacia y dedicación, cuando un día, enferma, y debe internarse para su atención, es entonces cuando sus patrones, por quienes ella siempre se desveló, no solamente la abandonan a su suerte, sino que hasta le exigen que de sus ahorros, pague a otra persona para que la reemplace en las tareas de la casa de sus patrones [...] siguió trabajando en verdadero estado de enfermedad hasta que sus fuerzas físicas ya agotadas completamente, remató con el hecho de que sus patrones la despedían, sin preavisarle ni reconocerle, sus sueldos, los gastos de su enfermedad. [...] agotados todos los recursos extrajudiciales, recurre hoy a la justicia para que los señores jueces, haciendo justicia con la ley, sancionen a quienes tanto se lo merecen... ${ }^{34}$

Tanto trabajadoras como empleadores hacían descansar sus estrategias ante las instituciones de justicia no sólo en argumentos estrictamente legales, sino también en la construcción de imágenes morales de sí y de sus oponentes. Este tipo de estrategias es común a otros fueros y otros períodos. Sin embargo, en el caso del servicio doméstico, puede observarse una peculiaridad: muchas veces esas estrategias se centraban en el valor moral otorgado a un trabajo realizado en el marco de relaciones que excedían lo laboral e implicaban una reciprocidad fundada en su carácter familiar afectivo. En este sentido, en el fragmento transcripto puede verse que la trabajadora buscaba un reconocimiento que excedía el dinero reclamado por el trabajo realizado, así como una "sanción" hacia aquellos a quienes había tratado con afecto y que, sin embargo, no habían sido recíprocos cuando ella lo había necesitado.

En otros casos, la búsqueda de dicho reconocimiento estaba más explícitamente vinculada a la identificación de la trabajadora con la figura de la madre y el ama de casa. En una demanda iniciada ante el Tribunal del Trabajo Doméstico en 1960, por ejemplo, la trabajadora destacaba que, entre sus labores, se ocupaba de la hija de su empleadora, "a la que dispensó el cuidado que requería la paciente, a tal punto que llegó a considerarla como de la familia", lo que implicaba que, dadas sus responsabilidades de cuidado, no podía gozar de las horas de descanso obligatorias. ${ }^{35}$

El lugar de ama de casa y madre era disputado por trabajadoras y empleadoras en el marco de las estrategias discursivas desarrolladas frente a las instituciones de justicia. Así, por ejemplo, ocurría en un expediente iniciado en

\footnotetext{
${ }^{34}$ Acta 206/1960, Tribunal del Trabajo Doméstico, Archivo General de la Nación.

${ }^{35}$ Acta 223/1960, Tribunal del Trabajo Doméstico, Archivo General de la Nación.
} 


\section{Inés Pérez}

1966, en el que una trabajadora reclamaba sueldos, aguinaldos y vacaciones de toda la relación de trabajo, sosteniendo que su empleadora nunca, en los cinco años que había trabajado para ella, se los había pagado. En su defensa, la empleadora sostuvo que era inverosímil que "una sirvienta no [tuviera] necesidad alguna de comprar ropa, calzado, peluquería y otros gustos que se daba, que no fuera del sueldo que percibía mensualmente el que disponía a su gusto". La empleadora llamó a distintos testigos que, sin embargo, no hicieron referencia alguna a la cuestión clave del reclamo: la ausencia del pago de salarios. Los testigos de la empleadora, en cambio, reiteradamente dieron fe de que ella "viv[ía] dedicada exclusivamente al cuidado de su hijo y a sus cátedras, llevando una vida completamente honesta". 36

La demanda, en efecto, excedía la cuestión de los salarios y los derechos laborales, poniendo en el centro la moralidad de la empleadora -y, como espejo, la de la trabajadora-. En el diseño del pliego de posiciones, la trabajadora sostenía que

Cuando nació el hijito que tiene [la empleadora], le prometió un aumento de sueldo... para que también le atendiera al hijito, como si fuera una madre", "que tal atención del menorcito... la realizaba la ponente durante todo el día, inclusive muchas noches porque la señora absolvente salía de paseo. Que la absolvente se hallaba ausente del domicilio durante todo el día... Que por tal razón el varoncito quería más a la ponente que a la madre. ${ }^{37}$

Si la empleadora era caracterizada como una madre desapegada, con una moral sexual dudosa, la trabajadora, en cambio, era presentada como una "madre" sustituta devota y cariñosa. La referencia al niño que debía cuidar a partir de diminutivos y la insistencia en que él quería más a la trabajadora que a su propia madre confirmaban la superioridad moral de la trabajadora. La defensa de la empleadora, por su parte, implicaba una delimitación de las tareas de su empleada. Sostenía, por ejemplo, que debido a los eccemas que la trabajadora tenía en los brazos y manos, no podía hacer muchas de las tareas domésticas. Insistía, además, en que no le permitía acercarse a su hijo para evitar que lo contagiase. Tanto empleadora como empleada organizaban sus estrategias frente al TSD como una competencia por el lugar de madre y ama de casa.

La centralidad de estas figuras se apoya en distintas transformaciones ocurridas en este período. Por un lado, las décadas centrales del siglo XX fueron el escenario de una reedición del modelo de mujer doméstica y de una nueva visibilidad pública del ama de casa. ${ }^{38}$ Aunque este modelo se identificaba con la

\footnotetext{
${ }^{36}$ Acta 337/1966, Tribunal del Trabajo Doméstico, Archivo General de la Nación.

37 ídem.

${ }^{38}$ Eduardo Elena, "Peronist Consumer Politics and the Problem of Domesticating Markets in Argentina, 1943 - 1955", Hispanic American Historical Review, Vol. 87 No. 1, 2006, [111-149]; Natalia Milanesio, "The Guardian Angels of the Domestic Economy": Housewives' Responsible Consumption in Peronist Argentina", Journal of Women's History, Vol. 18 No. 3, 2006, [91-117];
} 


\section{Género y derechos laborales}

clase media, su apropiación por parte de las mujeres de sectores trabajadores, y en particular por las empleadas domésticas, fue impulsada desde distintos espacios. ${ }^{39}$ Por otro lado, las redefiniciones del servicio doméstico ocurridas desde principios de siglo a las que ya hiciéramos referencia lo acercaron al trabajo doméstico no remunerado. Resulta significativa la inclusión de la figura del ama de casa en las discusiones sobre la regulación de este empleo en la década de 1950.40 A pesar de que distintos proyectos de regulación del servicio doméstico fueron presentados en el congreso desde los años veinte, no fue sino hasta el debate del proyecto de Delia Parodi que tuviera lugar en 1955 que el "ama de casa" se convertiría en un sujeto relevante en esa discusión. Su inclusión en los considerandos del Decreto Ley 326, como contraparte de la figura de la empleada, marca un cambio en la forma en que este trabajo era socialmente percibido.

El cuidado prodigado por las trabajadoras y la relación afectiva establecida con los empleadores y su familia podía dar lugar a la búsqueda de una reparación simbólica, más allá de los derechos laborales definidos de manera estricta. En este caso, sin embargo, no se trata sólo del afecto involucrado sino de la forma maternalista que había asumido la relación entre trabajadora y empleadora. La trabajadora y su abogado pedían a los testigos que respondieran "si sab[ían] y cómo les consta[ba] que la señora... decía que le depositaba el sueldo en caja de ahorros para que la firmante no se lo gastara o para que algún chinito la enamorara y le sacara la plata". ${ }^{41}$ La actora sostenía, además, que la empleadora no le había concedido vacaciones ni dejaba que saliese en su día libre porque "como provinciana de tierra adentro, [la iban] a embaucar". ${ }^{42}$ La demanda de la trabajadora frente al Tribunal del Trabajo Doméstico puede leerse como una contestación a los estereotipos étnicos, de clase y género que aparecen en los fragmentos recién citados. De acuerdo a la trabajadora, la empleadora presentaba el incumplimiento de sus derechos laborales básicos como una forma de protección, tratando a la trabajadora como una niña incapaz de manejar dinero. En este sentido, el reclamo ante las instituciones de justicia implicaba el reconocimiento de la trabajadora como una ciudadana que conocía sus derechos.

Inés Pérez, El hogar tecnificado. Familias, género y vida cotidiana (1940-1970), Buenos Aires: Biblos, 2012.

${ }^{39}$ Lilia Vázquez Lorda, "El otro ángel del hogar es mujer, trabajadora y asalariada. Las empleadas domésticas y el catolicismo en la Argentina de los años 1950", en Norberto Álvarez, comp., Familia, género y después... Itinerarios entre lo público, lo privado y lo íntimo, Rosario: Prohistoria, 2010 [107-126]; Rebekah Pite, "Entertaining Inequalities: Doña Petrona, Juanita Bordoy, and Domestic Work in Mid-Twentieth-Century Argentina", Hispanic American Historical Review, Vol. 91 No. 1, 2011, [97-138].

${ }^{40}$ Ania Tizziani, ob. cit.

41 ídem.

42 Ídem. 


\section{Inés Pérez}

$\mathbf{V}$

A lo largo del siglo XX, el servicio doméstico ha ocupado un lugar ambiguo entre los mundos laboral y familiar. En términos legales, la cercanía entre el servicio doméstico y el trabajo doméstico no remunerado fue construida a partir de la sanción de distintas normas que redefinieron el servicio doméstico, excluyendo de su seno aquellas ocupaciones consideradas "calificadas" o que tenían un vínculo más estrecho con el mundo "público". Las trabajadoras domésticas quedaron así excluidas de los derechos garantizados contemporáneamente a otros trabajadores y trabajadoras, exclusión que fue confirmada con la sanción de la Ley de Contrato de Trabajo, en 1974.

Para 1956, cuando fue sancionado el decreto ley 326, la figura del ama de casa había ganado un lugar relevante en la discusión sobre los derechos laborales de las trabajadoras domésticas. Tanto las transformaciones legales como los cambios en la forma en que era prestado este trabajo -que habían implicado el crecimiento del empleo con retiro así como la reducción de la cantidad de trabajadoras por hogar y el crecimiento de la cantidad de empleadores de sectores medios-, llevaron a identificar a las trabajadoras domésticas con la "empleada para todo servicio", cuyo trabajo era asimilable al que las mujeres realizaban en sus hogares sin una remuneración a cambio.

El supuesto de que el trabajo doméstico debía ser gratuito en el marco de ciertas relaciones afectivo familiares fue, en efecto, utilizado recurrentemente por quienes eran demandados ante distintas instituciones de justicia laboral por derechos derivados de relaciones del servicio doméstico. Si bien el decreto 326 había buscado establecer un criterio claro para distinguir el servicio doméstico de otras formas de trabajo doméstico frente a las que no correspondía una remuneración, la invisibilidad del trabajo realizado puertas adentro y las relaciones de ambigüedad afectiva ${ }^{43}$ entabladas entre empleadores y trabajadoras domésticas permitían este tipo de estrategias judiciales. En este sentido, dicha cercanía fue utilizada de diferentes formas para negar a las trabajadoras distintos derechos.

Sin embargo, la cercanía entre el servicio doméstico y el trabajo doméstico no remunerado y la ambigüedad afectiva de las relaciones establecidas en ese marco también fueron utilizadas en las estrategias de las trabajadoras domésticas. La apelación al valor moral del trabajo realizado en el marco de relaciones afectivo familiares, sin embargo, resulta más visible en los registros de ciertas instituciones que en los de otras y en ciertos períodos históricos que otros. El Tribunal del Trabajo Doméstico, que tenía un procedimiento más horizontal, era un ámbito más permeable a estos discursos que los tribunales de trabajo regulares. Por otra parte, los expedientes iniciados durante los primeros años de su funcionamiento muestran los discursos de las trabajadoras de una manera menos mediada que los

${ }^{43}$ Donna Goldstein, Laughter Out of Place. Race, Class, Violence, and Sexuality in a Rio Shantytown, Berkeley y Los Ángeles: University of California Press, 2003. 


\section{Género y derechos laborales}

que se iniciaran en años posteriores: abogados y representantes sindicales, aunque importantes, aún no habían desarrollado el discurso cristalizado que puede observarse desde fines de los años sesenta. Si bien esto no quiere decir que este tipo de reivindicaciones estuvieran ausentes de las demandas iniciadas ante otras instituciones o en otros períodos, sus huellas resultan más débiles.

La apelación de las trabajadoras a dicha cercanía puede leerse como parte de las estrategias discursivas que las y los actores sociales han exhibido en distintos contextos frente a las instituciones de justicia. Ahora bien, el valor otorgado al trabajo doméstico en los expedientes analizados, que excede en muchos casos el dinero reclamado, se sitúa en un tipo de trabajo atravesado por relaciones de ambigüedad afectiva, caracterizadas simultáneamente por una marcada proximidad e intensas desigualdades. Se sitúa, además, en un contexto particular en el que dicho trabajo y la figura del ama de casa habían ganado una nueva relevancia.

Más allá de las particularidades de dicho contexto, dicha apelación nos lleva a reflexionar acerca de las formas de valorizar un trabajo que, relegado a la esfera doméstica, ha sido caracterizado por su invisibilidad. En tanto los derechos sociales dependen del empleo, quienes desempeñan trabajos que no resultan claramente asimilables a esa condición verán sus derechos disminuidos. Por otro lado, como ha mostrado Susan Himmelweit, asimilar el "trabajo doméstico", remunerado o no, a lo que en la modernidad se ha definido como "trabajo" -desde una perspectiva androcéntrica- implica cierto reduccionismo respecto, entre otras cosas, de los aspectos emocionales implicados en él. ${ }^{44} \mathrm{Si}$ la afectividad ha sido usada para negar derechos a las trabajadoras, la afectividad también aparece como sustento de derechos. El escenario actual, en el que la discusión sobre los derechos de las trabajadoras domésticas ha ganado un renovado impulso a nivel nacional e internacional, representa una oportunidad para pensar formas de valorización que den cuenta de las complejidades que reviste este tipo de trabajo.

\footnotetext{
${ }^{44}$ Susan Himmelweit, "El descubrimiento del trabajo no pagado" en Dinah Rodríguez y Jennifer Cooper, ob. cit. [251-276].
} 